\author{
EVS29 Symposium \\ Montréal, Québec, Canada, June 19-22, 2016
}

\title{
Switched On Scotland: Implementing Scotland's Roadmap to Widespread Adoption of Plug-in Vehicles
}

\author{
David A. Beeton ${ }^{1}$, Stephen Davison ${ }^{1}$, Zak Tuck ${ }^{2}$, \\ ${ }^{I}$ Urban Foresight Limited, The Core, Science Central, Bath Lane, Newcastle upon Tyne, NE7 7ST, United Kingdom, \\ david.beeton@urbanforesight.org \\ ${ }^{2}$ Transport Scotland, Victoria Quay, Edinburgh, EH6 6QQ, Scotland, United Kingdom
}

\begin{abstract}
Summary
This paper explains the insights and lessons learned from developing the Scottish Government's Roadmap to Widespread Adoption of Plug-in Vehicles. This strategy drew on best practice from the fields of electric mobility and technology roadmapping to establish a comprehensive framework to guide future progress. This paper reviews the progress achieved to date in implementing this roadmap and explains the next steps to further advance the adoption of electric and hybrid vehicles in Scotland.
\end{abstract}

Keywords: BEV (battery electric vehicle), policy, strategy, promotion, UK

\section{Introduction}

In September 2013 the Scottish Government published an electric vehicle strategy that made headline news at home and around the world. Much of this publicity came from a bold vision to phase out emissions from fossil fuelled vehicles by the year 2050 and a comprehensive set of commitments to advance widespread adoption of electric and plug-in hybrid vehicles.

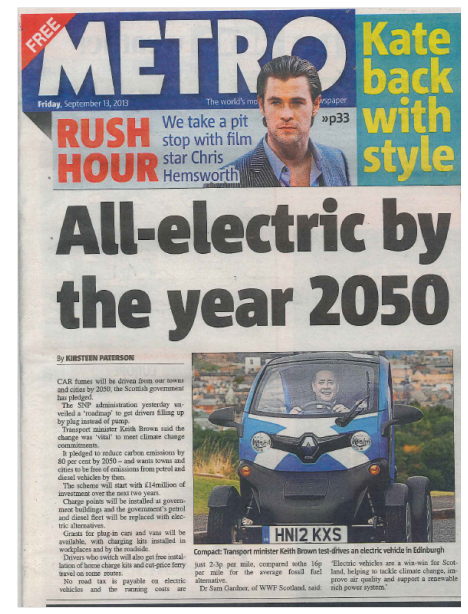

Figure 1. Launch of Scottish Government EV Roadmap featured on front page of a national newspaper.

The strategy, known as the Switched On Scotland Roadmap [1], was developed through a collaborative process that engaged over 120 experts that represented 78 different organisations from across the EV value chain. 
The production of the roadmap was also supported by the establishment of a high-level Strategic Board, which was jointly chaired by the Minister for Transport and a Senior Executive of an energy company. The Board comprised experts and influencers from actors working in local government, energy companies, charities, automotive manufacturers and e-mobility supply chain companies. Their input was sought to help formulate a strategic vision and shape the strategy.

It also drew on international best practice to create a comprehensive framework of enabling measures that needed to be implemented to facilitate the widespread adoption of plug-in vehicles.

This paper explains the key elements of the roadmap, providing insights on the thinking that informed its development and lessons to support other stakeholders to develop similar strategies. This paper also reviews progress achieved since publication of the roadmap, outlining a comprehensive portfolio of projects that have been developed to respond to the actions established in the strategy. Finally, it reviews the planned next steps as markets for electric vehicles transitions from early adopters to the next phase of uptake.

\section{Switched On Scotland Roadmap}

Transport Scotland is an agency of the Scottish Government with responsibility for transport policy in the country. Transport Scotland jointly developed the roadmap with Urban Foresight, a UK-based consulting think tank focused on future cities with detailed expertise in electric mobility and technology roadmapping.

This section outlines a number of key elements of the roadmap and overall architecture of the roadmap.

\subsection{Vision}

The roadmap established the ultimate ambition for all measures to promote EV uptake. As shown in Table 1 , the vision updated a previous ambition stated by the Scottish Government. There are a number of important elements that were considered in developing this new statement, including:

- To capture the imperative to reduce all emissions and not just carbon

- To avoid vague language such as "almost complete decarbonisation ... with significant progress..." in preference to the more confident, precise and time limited statements that assert "by $2050 \ldots . .$.

- To use emotive language such as "free from the damaging emission of..."

- To use prospect theory to explain the potential to gain something positive by using the words "will be free from..."

- To clarify the need to phase out fossil fuel vehicles as well as promoting EVs

- To highlight the local impacts and individual responsibilities by referring to "towns, cities and communities."

Table 1. Restating the Scottish Government's 2050 ambition.

\begin{tabular}{|l|l|}
\hline Scotland's Climate Action Plan (2009) & $\begin{array}{l}\text { Switched On Scotland: A Roadmap to } \\
\text { Widespread Adoption of Plug-in Vehicles (2013) }\end{array}$ \\
\hline $\begin{array}{l}\text { "Almost complete decarbonisation of road } \\
\text { transport by 2050 with significant progress by } \\
2030 \text { through wholesale adoption of electric } \\
\begin{array}{l}\text { cars and vans, and significant decarbonisation } \\
\text { of rail by 2050." }\end{array}\end{array}$ & $\begin{array}{l}\text { "By 2050, Scottish towns, cities and } \\
\text { communities will be free from the damaging } \\
\text { emissions of petrol and diesel fuelled } \\
\text { vehicles." }\end{array}$ \\
\hline
\end{tabular}

The vision further elaborated ambitions for achievements by 2030 and 2040. This was largely informed by a backcasting analysis of what needed to happen to realise the 2050 ambition, namely:

- By 2040 all new car sales would be near zero emissions at the tailpipe 
- By 2030 half of all fossil-fuelled vehicles will be phased-out of urban environments across Scotland.

A key area of debate in formulating this ambition was the merit of short-term targets. Some stakeholders engaged in this process felt that it was necessary to have targets for numbers of EVs/PHEVs on Scotland's roads by 2015 and 2020 . However, there was also a strong contention that this could ultimately prove to be counterproductive. This viewpoint was largely based on the rapid pace of change and developing understanding of the challenges and uncertainties in the early market for EVs. These changes meant that the analysis of equivalent targets that had previously been set by other countries showed that they were unlikely to reflect the expected development of the early market. This therefore raised a stark choice of setting a more realistic target that fell well short of the ambition of other countries, or committing to a target that was unlikely to be achieved. This was ultimately viewed to be unhelpful in building confidence in the early market for plug-in vehicles and potentially would distract from the highly ambitious 2050 vision, which portrayed a more significant long-term transformation that would impact everyone in Scotland.

\subsection{Outlook}

Figure 2 outlines a market growth scenario to achieve the roadmap vision. The scenario shows that a mix of low emission propulsion technologies will contribute, for example hydrogen fuel cell vehicles. This reflects the Scottish Government's technology neutral position on low emission vehicle solutions. However, plug-in vehicles are seen as the technology capable of making the most immediate impact in helping to achieve the key policy driver of Scotland's 2020 emissions reductions targets and are expected to be the majority technology for light duty vehicles in the lead up to 2050.

In the shorter term, the precise rate of growth in the use of plug-in vehicles will be influenced by a range of different factors, significantly the relative price of the vehicles and the rate at which they are brought to market.

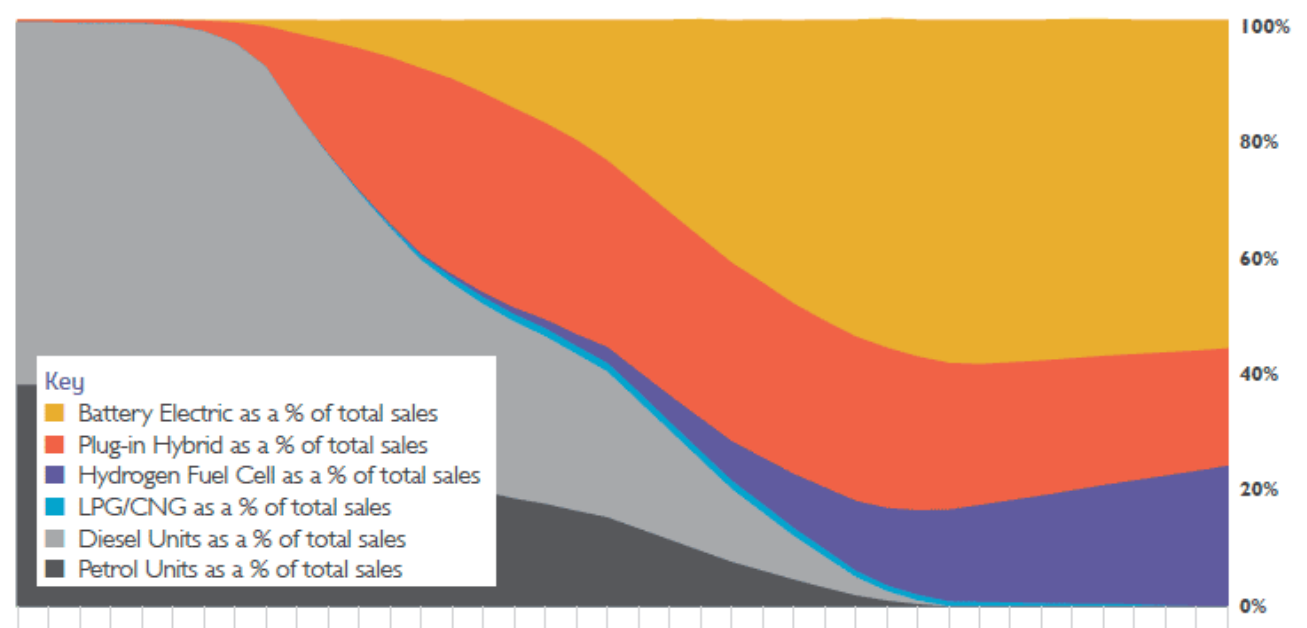

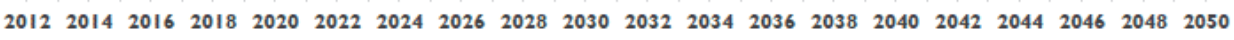

Figure 2. Outlook for low emission light duty vehicles in Scotland.

\subsection{An Integrated Framework}

The roadmap set out to establish everything that needed to happen in Scotland to realise the 2050 vision. This analysis was structured into seven areas shown as cogs in Figure 3. The intention was to explain the breadth of activity required. The use of cogs to illustrate this explains that for the strategy to function properly, all of these cogs needed to be turning in the right direction. Moreover, using this mechanical metaphor also explained that the machine would only turn as fast as the slowest moving cog. This challenged a number of preconceptions that government support for EVs should largely be focused on financial incentives and infrastructure provision. 


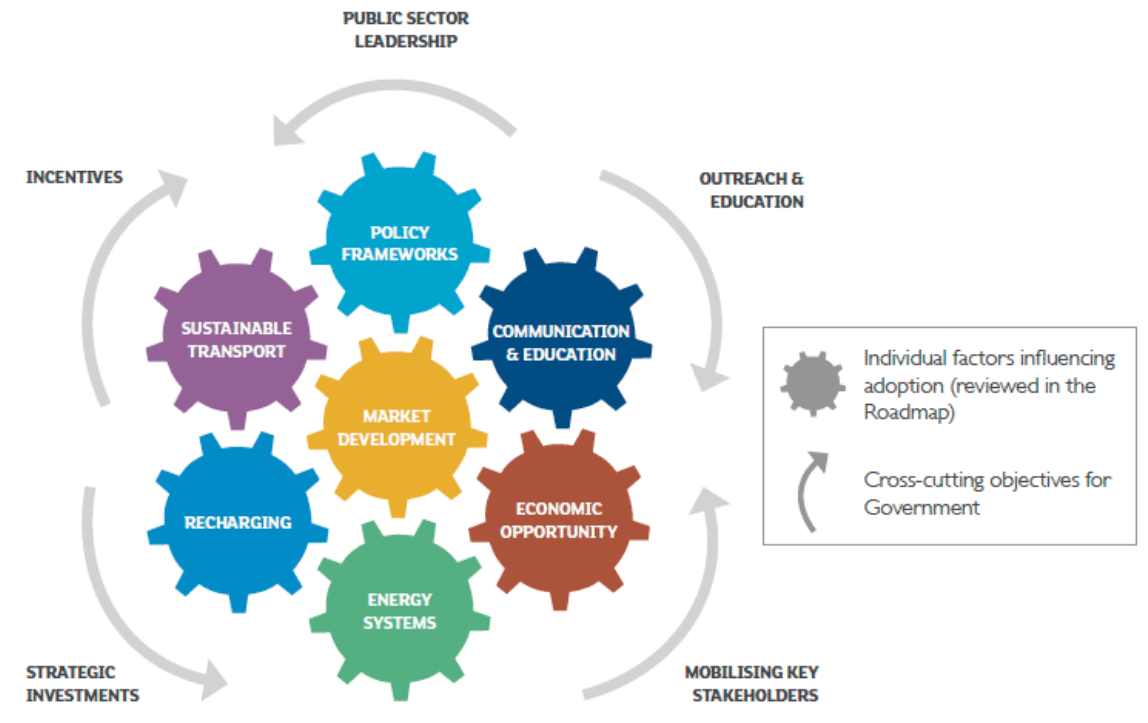

Figure 3. Framework developed for the roadmap.

Figure 3 also quantifies the five levers available to government to turn the cogs in the machine. This supported a broad evaluation of what government could do and to quantify exactly what needed to be done to bring about this change in Scotland, namely:

- Providing public sector leadership

- Making strategic investments

- Promoting incentives

- Mobilising key stakeholders

- Outreach and education

\subsection{Enabling Measures}

The insights collected in the workshops and from a review of international good practice were grouped into the seven sections represented by cogs in the framework. This led to the identification of 42 "enabling measures" across each of these seven areas, providing a comprehensive description of the changes that needed to take place to achieve the 2050 vision. This was intended to coordinate and align all stakeholders and signpost needs and opportunities.

As shown in Figure 4 each of these measures was placed in context of the timescales in which these changes were expected to be most important. An overarching goal was set for each of the seven areas and responsible organisations were also identified to support progress. 


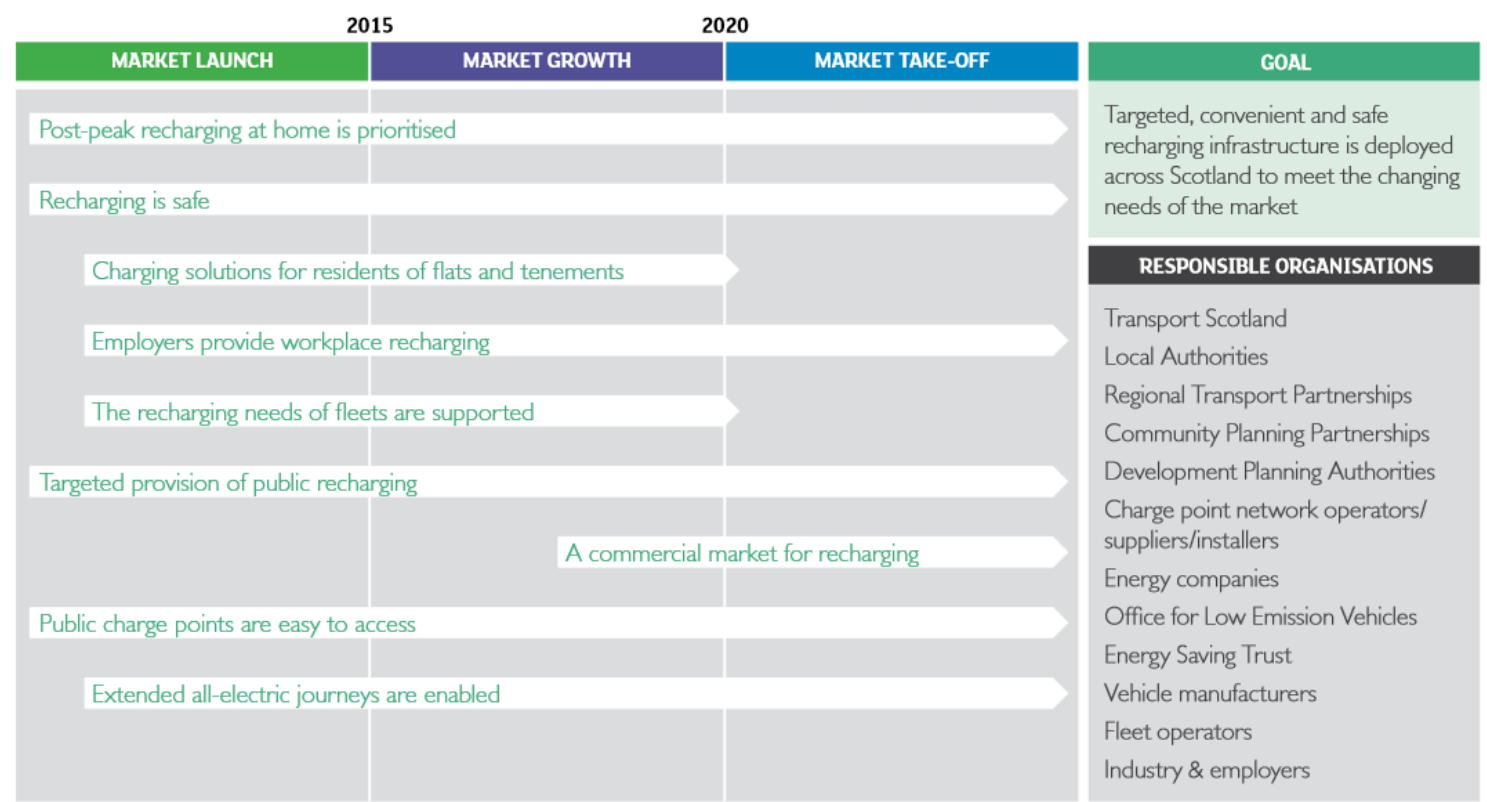

Figure 4. Enabling measures identified in the recharging infrastructure section of the roadmap.

\subsection{Actions for Government}

As well as defining the medium and long-term changes that need to take place in Scotland, in the form of enabling measures, the roadmap also established an action plan for government. This quantified 37 actions leading up to the end of 2015. This informed the continuation of existing projects and the development of new projects which are explained in the following section.

\section{Implementing the Roadmap}

The framework shown in Figure 3 provided a way to ensure that a comprehensive approach was taken across the seven areas identified:

- Policy frameworks

- Market development

- Recharging

- Energy systems

- Sustainable development

- Economic opportunities

- Communication and education.

The following sections explain the broad objectives set by the roadmap in each of these areas and summarise activities and initiatives that have be undertaken in Scotland to support progress.

\subsection{Policy Frameworks}

The roadmap establishes the need for the Scottish Government, the wider public sector and industry decisionmakers to individually and collectively establish policy frameworks that both guide and accelerate the widespread adoption of plug-in vehicles. It asserts that embedding plug-in vehicles into relevant national, local and organisational policies and strategies will motivate the required support, funding and commitments to change. It also recognises opportunities for plug-in vehicles to contribute to advances in related policy objectives.

A key action in the roadmap is for Transport Scotland to work with colleagues across Government and the public sector to support the development of policy frameworks that encourage the adoption of plug-in vehicles. This has led to a series of important developments since the publication of the roadmap in 2013: 
- In January 2016, Transport Scotland published a refresh of the National Transport Strategy. The refresh restated the key strategic outcome to reduce emissions to tackle climate change and improve air quality. Switched On Scotland and its vision feature in the strategy as part of the decarbonisation of road transport.

- In March 2016 it was announced that a new Energy Strategy for Scotland would take an integrated approach to power, transport and heat.

- In November 2015, the Scottish Government published Cleaner Air for Scotland, it's low emission strategy. The document confirms the commitment to decarbonise transport, clearly making the links between transport, air quality and health. The strategy makes a commitment to continue to deliver the actions contained in Switched On Scotland as part of increasing uptake of ULEVs.

- Strategies at a local level are also beginning to include specific references to increasing the use of EVs. The majority of local transport strategies written since the publication of the Roadmap in 2013 contain references to ULEVs.

- High level planning policy in Scotland recognises the importance of considering EV charging infrastructure in new developments. Both the Third National Planning Framework (NPF) and the Scottish Planning Policy 2014 (SPP) state the importance of the provision of charging infrastructure to achieve the ambitions of the Roadmap.

- A specific planning measure that has been implemented is the provision of permitted development rights for off-road charge points, which came into force on 30 June 2014.

\subsection{Market Development}

The transition from early to mainstream markets represents a considerable challenge. Past experience of introducing new technologies to the market has shown that strategies to promote EVs and PHEVs will need to respond to the requirements of different consumer groups beyond early-adopters. In particular, the roadmap advocates that promoting mainstream adoption requires a move away from the historical emphasis on pilots and trials which create a perception that EVs are a novel, niche or experimental technology. The roadmap establishes the need to focus on supporting commercialisation and stimulating market growth, with the ultimate objective to promote plug-in vehicles as more desirable than fossil-fuelled alternatives.

Since the publication of the roadmap, Scotland experienced a four-fold increase in the number of ultra low emission vehicle sales in 2014 and a further increase in 2015. There have been a number of initiatives to support this growth targeting public and private sector organisations as well as individuals:

- In addition to the UK Government's plug-in car and van grant, the Scottish Government has provided interest free loans to purchase ultra low emission vehicles. The scheme provides interest-free loans of up to $£ 100,000$ to businesses, including taxi operators, to encourage them to switch to EVs. A loan of up to $£ 50,000$ is available to individuals. The scheme has proved so popular that it was oversubscribed for 2015/16.

- Local authorities across Scotland are offering a range of local incentives to promote uptake of EVs including free parking and using licencing to encourage uptake for taxis and private hire vehicles. Many local development plans in Scotland also now include at least the consideration for provision of charge points in new developments.

- The Switched On Fleets initiative offers free, evidence-based analysis, identifying new opportunities for the cost effective deployment of EVs across the public sector in Scotland. Transport Scotland has provided $£ 2.5$ million of grant funding to enable these partnerships to buy or lease EVs. The initiative ran from 2014 to 2016, and the first year of operation saw 145 new EVs introduced across the fleets of 22 public sector organisations.

- The Scottish Green Bus Fund (SGBF) provides the opportunity for interested parties (e.g. operators, local authorities, regional transport partnerships) to bid for a grant to help towards the purchase of new Low Carbon Emission Buses (LCEBs). The Fund, through five rounds, has now provided almost $£ 13$ million of funding, enabling 269 new LCEBs to join the Scottish fleet. Initiatives such as the SGBF have also contributed to the establishment of Alexander Dennis Limited as a leading supplier of low carbon hybrid-electric buses.[2] 


\subsection{Recharging}

A major advantage of plug-in vehicles compared to other alternatively-fuelled transport solutions is that the majority of infrastructure is already in place in the form of a nationwide electricity grid. The key task is therefore to focus on ensuring that the final elements of this infrastructure, namely the charge points, are safely deployed to meet the changing needs of the market. Importantly, supporting growth in markets for plug-in vehicles does not require the provision of charge points on every street corner across Scotland. This would be both unnecessary and uneconomic, with the potential for underutilised charge points damaging public confidence. Accordingly, the task is to ensure that charge points are provided in the places in which they are most needed. This relates to both the locations in which they would be most used and also where recharging would enable plug-in vehicle drivers to achieve the journeys that they wish to make.

There has been a significant increase in the number and use of charge points in Scotland the past few years resulting in Scotland having the highest ratio of charge points per household in Great Britain, after North East England.

- Through its ChargePlace Scotland programme, Transport Scotland has now installed 806 charge points including 584 publically available charge points and 222 work place charge points. This has resulted in over 1,100 publically available charging bays.

- The roadmap's target for rapid chargers at intervals of every 50 miles has been achieved and the Scottish Government has since strengthened its commitment to every 35 miles.

- The Switched on @Work programme was set up in 2015 to support organisations to interested in providing charge points for their employees. The programme offers organisations tools and technical assistance including assessing workplace demand.

\subsection{Sustainable Transport}

The roadmap recognises that an efficient and sustainable transport system is essential for Scotland's economy, communities, environment, health and general wellbeing. Accordingly, it establishes that measures to promote plug-in vehicles also need to advance improvements in the overall quality and sustainability of Scotland's transport system rather than adding to existing problems.

There has been targeted investment to provide charge points at hubs for multi-modal journeys.

- Abellio ScotRail Limited have committed to providing at least two electric car charging bays in each of at least 50 train station car parks by the end of November 2017. Abellio will also promote low emission car usage by offering lower parking tariffs with discounts of up to $15 \%$ to customers with Low Emission Vehicles.

- The Developing Car Clubs in Scotland programme supported the purchase of new EVs into car sharing operations. As a result, around $25 \%$ of the Scottish car club fleet being electric. Scottish car clubs currently have just over 8,700 members and a fleet of 345 vehicles, across 24 locations.

- Charge points have been installed at eleven ferry terminals.

- To incentivise the use of low emission transport and active travel, the Scottish Government and local authorities are working to understand how low emission zones can most effectively be used to improve air quality. The low emission strategy, Cleaner Air for Scotland, outlines the process for establishing the National Low Emission Framework. The framework will include a standard appraisal process for assessing local air quality measures. The options included in the framework are: low emission zones; clean air zones; other access regulation schemes; traffic management; and, vehicle licencing regulations.

\subsection{Energy Systems}

As increasing numbers of vehicles enter the market it is essential to ensure that the grid is sufficiently robust and well-managed to accommodate any changes in demand. A further key opportunity is to fully realise the potential of plug-in vehicles to support the development of a cleaner and smarter energy system. 
- The most significant development is the Scottish Government's 2016 commitment to develop an Integrated Energy Strategy which takes a whole-system approach to transport, power, and heat.

- In 2015 the Scottish Government commissioned the development of a Whole System Energy Model for Scotland which will take into consideration all of the key elements of the Scottish system, from production to end-use, including transport, power and heat. The explores Scotland-specific energy futures and to support future policies and proposals to enable Scotland to meet its climate change and renewable generation targets.

- The opportunities for integration between energy and transport policy were reviewed in a study undertaken by Urban Foresight for Transport Scotland.

- The My Electric Avenue project tested monitoring and control technology by recruiting 'clusters' of EV users, both residential and business, to simulate a 2030 network and provide essential learning about managing the strain on the electricity distribution network from the anticipated increased uptake of electric vehicles.

\subsection{Economic Opportunity}

The roadmap establishes that advancing plug-in vehicles not only offered the potential to limit the effects of climate change and poor air quality, but also to capitalise on the economic opportunities that arise from these actions. The benefits to Scotland will accrue in the form of a secure domestic economy which is underpinned by sustainable low carbon activity and the development of new goods and services. This in turn will enhance Scotland's reputation as a key destination for low carbon investment. Furthermore, at the operational level, advancing plug-in vehicles also offers potential to make Scottish companies more efficient, profitable and competitive.

- To promote Scotland as a leading EV nation, the E-cosse partnership has been leading an international dissemination programme, presenting Scotland's story at a range of international events.

- Scottish companies have also been active in securing investments in R\&D and new technologies for electric vehicles. For example, in March 2016, seven technology companies in Scotland received a share of $£ 2.5 \mathrm{~m}$ from the UK Government for emission-cutting technology projects. Projects include: Sunamp Ltd leading a team to transform chilled or frozen food fleets using 'thermal store' technology to minimise battery power used up to keep food deliveries fresh; and, AGM Batteries Ltd working on sodium-ion batteries for EVs.

- A review of the existing and future training and skills needed to support widespread adoption of ultra low emission vehicles has also been undertaken to ensure that Scotland can anticipate and respond to these requirements.

\subsection{Communication \& Education}

To encourage widespread adoption of plug-in vehicles, the roadmap recognises it will be essential to complement the measures highlighted in previous sections by promoting increased awareness and influencing attitudes and skills in order to build confidence in purchasing and using plug-in vehicles. This requires engagement with individuals, organisations and key influencers in the public and private sector.

- Regular practitioner forums are organised by the E-cosse partnership to bring together a wide range of stakeholders from across the EV sector. Eleven forums have taken place to the end of 2015 on topics as diverse as integrating EVs into fleets; business cases for large scale adoption of EVs into fleets; local incentives; communications and outreach; development of the EV market and, energy systems. There have been over 600 attendees at the forums representing over 150 organisations from the public and private sector.

- There has been a broad programme of public outreach and engagement activities to engage a wide number of people through a range of media. For example, the Energy Saving Trust has led a 
programme of events across Scotland including roadshows, EV hotspot events and, in September 2015, Scotland's first EV rally when around 60 EVs made the 60 mile round trip between Glasgow and Stirling.

- The Energy Saving Trust offers FuelGood training to businesses for their drivers to learn how to get the most miles from a single battery charge.

- GreenFleet is an event specifically designed for fleet managers to demonstrate the viability of ULEVs to organisations that want to improve the efficiency of their fleet.

- EVolution is an event designed for the whole family to gain wider knowledge and experience of ULEVs. The events in 2014 and 2015 attracted over 2,000 attendees.

\section{Conclusions and Next Steps}

This paper explains the insights and lessons learned from developing the Scottish Government's Roadmap to Widespread Adoption of Plug-in Vehicles. The key elements of this roadmap that would be recommended for consideration by practitioners developing similar strategies are:

- A bold long-term vision that established the scale of the transformation that needs to take place in Scotland.

- An outlook that explained that a range of technologies would likely contribute to this vision, and that achieving this required the phasing out of fossil fuelled vehicles as well as promoting ultra low emission alternatives.

- An integrated framework to communicate the need for a holistic approach across a number of important areas to achieve the goals established by the roadmap.

- An action plan for government which explained the measures that it could take to influence uptake of EVs, but also recognised the limitations of this influence and the need to mobilise other stakeholders with the necessary resources and expertise to bring about this change.

The roadmap also provided an extremely practical framework to guide investments and activity across multiple different stakeholders. This paper has outlined many important developments that have occurred since the publication of this strategy, which are

At the time of writing this paper, Urban Foresight was undertaking a formal review of the Switched on Scotland roadmap for Transport Scotland. It is expected that this review will quantify the progress made since the publication of the roadmap and outline an action plan for the next phase of activity.

As shown in Figure 5, the roadmap established that the challenge faced is to evolve strategies that were designed to support the launch of markets for EVs, to now focus on achieving growth and supporting the eventual take-off, achieving the ultimate objective of widespread adoption of plug-in vehicles in Scotland.

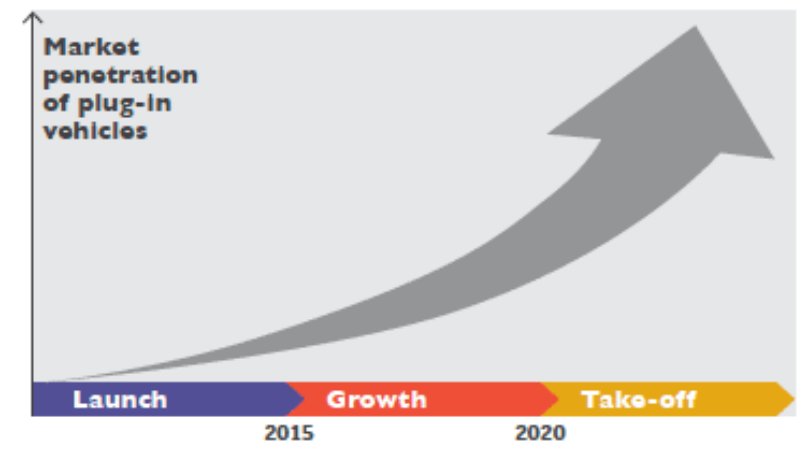

Figure 5. Three phases of market penetration of plug-in vehicles. 


\section{References}

${ }^{[1}$ Transport Scotland and Urban Foresight (2013) Switched On Scotland: A Roadmap to Widespread Adoption of Plug-in Vehicles. Available at: http://www.transport.gov.scot/report/j272736-00.htm, Accessed: 24 March 2016

${ }^{2}$ Transport Scotland, (2016). National Transport Strategy. Available at: http://www.transport.gov.scot/strategy/national-transport-strategy, Accessed: 24 March 2016

\section{Authors}

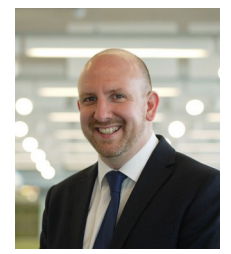

Dr. David Beeton holds two Masters degrees in Engineering, an MBA and a PhD in Technology Management from University of Cambridge for his research into the use of technology roadmapping for sector foresight. As Managing Director at Urban Foresight, David leads a consulting think tank that develops strategies and projects focused on future cities. This includes leading a global task force for International Energy Agency IA-HEV on EV Business Models and a government-led industry collaboration to advance EV adoption in Scotland. David was also the lead author of the EV City Casebook. David received a best presentation award for his paper at EVS28 in Seoul.

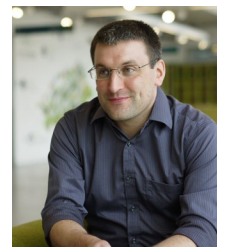

Stephen Davison is an experienced analyst with a background in science, finance, social research and economics. With broad experience of quantitative and qualitative research methods, he specialises in designing and conducting evaluations with a focus on cost-benefit and value for money. Stephen has a strong track record of producing analysis that influences decision making within organisations and beyond. He holds a Masters in Regional Development from Newcastle University, and degrees in Social Sciences with Economics and Astronomy and Astrophysics.

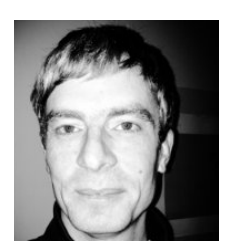

Zak Tuck is Head of Low Carbon Vehicle Policy at Transport Scotland. Zak graduated from Aberdeen University with a BSc Hons in Biomedical Science and an MSc in IT \& Intelligent Systems. He joined the, then, Scottish Executive in 2004 and has worked in a variety of policy areas including natural heritage, cancer screening, regeneration, marine planning and transport strategy. He is currently head of the Low Carbon Vehicle Policy Team in Transport Scotland, which is focused on delivering the Scottish Government's vision of freeing Scotland's towns, cities and communities from the damaging effects of fossil-fueled vehicles by 2050 . 